\title{
Article \\ Comparison of Pharmaceutical Characteristics between Brand-Name Meropenem and Its Generics
}

\author{
Ping Yang ${ }^{1}{ }^{\oplus}$, Shigeru Fujimura ${ }^{2, *}$, Yawei Du ${ }^{1}$, Bei Zhang ${ }^{1}$, Li Yang ${ }^{1} \oplus$, Masato Kawamura ${ }^{2}$, Zhenhua Zhang ${ }^{3}$ \\ and Suodi Zhai ${ }^{1, *}$ \\ 1 Department of Pharmacy, Peking University Third Hospital, Beijing 100191, China; \\ guoguokate@163.com (P.Y.); duyawei2K@sina.com (Y.D.); zhangbei26@126.com (B.Z.); \\ lilianyangli@163.com (L.Y.) \\ 2 Division of Clinical Infectious Diseases \& Chemotherapy, Tohoku Medical and Pharmaceutical University, \\ Sendai 981-8558, Japan; m-kawamura@tohoku-mpu.ac.jp \\ 3 Department of Medical Affairs, Sumitomo Pharmaceuticals (Suzhou) Co. Ltd., Shanghai 200025, China; \\ zhangzh@dsmpharm.com.cn \\ * Correspondence: sfuji@tohoku-mpu.ac.jp (S.F.); zhaisuodi@163.com (S.Z.)
}

Citation: Yang, P.; Fujimura,

S.; Du, Y.; Zhang, B.; Yang, L.;

Kawamura, M.; Zhang, Z.; Zhai, S.

Comparison of Pharmaceutical

Characteristics between Brand-Name

Meropenem and Its Generics.

Antibiotics 2021, 10, 1096. https://

doi.org/10.3390/antibiotics10091096

Academic Editor: David P. Nicolau

Received: 12 August 2021

Accepted: 8 September 2021

Published: 10 September 2021

Publisher's Note: MDPI stays neutral with regard to jurisdictional claims in published maps and institutional affiliations.

Copyright: (c) 2021 by the authors. Licensee MDPI, Basel, Switzerland. This article is an open access article distributed under the terms and conditions of the Creative Commons Attribution (CC BY) license (https:// creativecommons.org/licenses/by/ $4.0 /)$.
Abstract: This study aimed to provide comparative information of pharmaceutical properties, including particle morphology and distribution uniformity, solubility, presence of residual solvent and insoluble particles, and antimicrobial activities, between brand-name meropenem (Mepem ${ }^{\circledR}$, BNM) and its six generic products (GPs A-F) marketed in China. Particles of GP-A and -C in dry powder had similar diameters of BNM, while other GPs were larger. Only BNM and GP-A were completely dissolved within $100 \mathrm{~s}$ in the lab condition. No insoluble particles $>25 \mu \mathrm{m}$ in diameter were detected in BNM and GP-E. Regarding stability of GPs solutions evaluated by concentration of open-ring metabolites at $6 \mathrm{~h}$ and $8 \mathrm{~h}$, BNM showed the lowest open-ringed metabolite concentrates. Residual solvent of acetone detected in one GP showed the maximum value, while ethanol and ethyl acetate were detected both in product $\mathrm{E}$ and product $\mathrm{F}$. The concordance rates (\%) of minimum inhibitory concentration (MIC) of each generic compared to BNM were 89.5, 85, 87.5, 88, 88.5, and 86.5, respectively, although no significant difference was reached in MIC. Pharmaceutical characteristic differences between the BNM and GPs identified in this study could provide insights into understanding the deviations in the drug manufacturing processes of generic drugs.

Keywords: meropenem; dissolution time; stability; morphology of particles; antimicrobial susceptibility patterns

\section{Introduction}

Generic drugs must contain the same quantitative and qualitative composition of active ingredients compared to their brand-name counterparts [1-4]. The prescription of generic drugs is an effective approach for reducing the cost $[5,6]$ and increasing global access to first-line medication for the treatment of diverse diseases. In 2010, generic antibiotics represented more than two-thirds of the global consumption of medications [7]. Currently, generics are being used widely $[8,9]$.

The marketing approval of the brand-name drugs requires the completion of Phase I-III clinical trials. The brand-name products might be required to conduct additional post-marketing studies [10] after they are on the market to test their safety and effectiveness in a large number of people. In order to achieve in vivo clinical equivalence, the quality of the brand-name drug and the generics should be consistent in vitro [11]. Based on the data of pharmaceutical consistency and bioequivalence (BE) studies, the generic products can be approved quickly. For drugs that are intravenously administered, only a pharmaceutical consistency test is required in most cases. Minor differences in ingredient composition and excipients might occur during manufacturing processes, and these minor differences might be tolerated in a consistency test. 
Meropenem is one of the carbapenems often used in the treatment of severe infections [12-14], and for the treatment of infections due to drug-resistant Pseudomonas aeruginosa and Enterobacteriaceae [15-18]. Meropenem generics have been widely used across the world. Previous studies have characterized differences between brand-name meropenem and its generics marketed overseas in terms of pharmaceutical features as well as therapeutical efficacies [11,19-22]. Previous studies compared brand-name meropenem and its generics in Colombia and found that the therapeutic nonequivalence of meropenem products might be attributed to the different susceptibility to dihydropeptidase I (DHP-I) hydrolysis [20]. Studies conducted in Japan showed that brand-name meropenem and its generic products are different in dissolution time, which might be associated with the differences in the size of bulk particles and the amount of solubilizer [19]. In addition, it has been characterized that meropenem generics marketed in Europe had different dissolution times and stability compared to its originator product [11]. Studies conducted in India [22] described a method for the determination of relative potency of various generic brands of antibiotics and showed that in terms of active pharmaceutical ingredient, not all generics are inferior. Taken together, previous studies provided comparative data between brand-name meropenem and its generics marketed overseas. However, pharmaceutical differences between meropenem BNM and its generics manufactured and sold in China have not been reported.

The present study aimed to compare the differences in pharmaceutical characteristics with respect to morphology by scanning electron microscopy (SEM), dissolution time, insoluble particles, stability, residual solvent, and antibacterial activity between brandname meropenem (BNM) $\left(\right.$ Mepem $\left.^{\circledR}\right)$ and its six major generic products in China.

\section{Results}

\subsection{Particle Morphology Characterization under SEM}

Results of the SEM of particles are displayed in Figure 1. The particle diameters of GP-A and -C were similar to that of BNM (about $40 \mathrm{~nm}$ ), whereas the diameters of other GPs were greater than $80 \mathrm{~nm}$. It can also be observed that meropenem particles of BNM, GP-A, and -C were evenly distributed and formed a more uniform mixture compared to other generics.

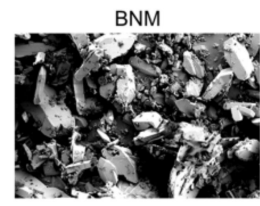

GP-C

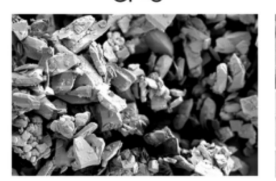

GP-F

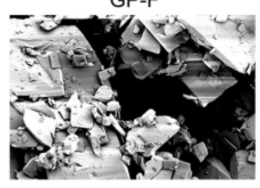

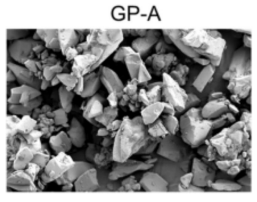

GP-D
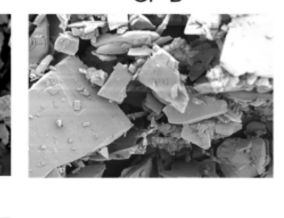

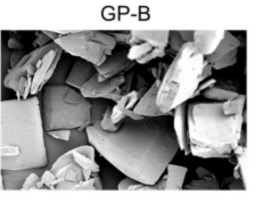

GP-E

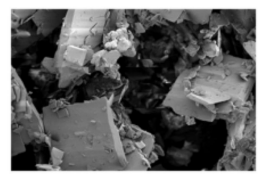

Magnification: X500 $-20 \mathrm{~mm}$

Figure 1. Images of particles of brand-name meropenem (BNM) and six generic products (GP-A to -F) using scanning electron microscopy. Magnification: $500 \times$.

\subsection{Dissolution Time Measurements}

Comparisons of the dissolution test of BNM and GPs under laboratory conditions are demonstrated in Figure 2. BNM and GP-A were completely dissolved within $100 \mathrm{~s}$, while the others required at least $120 \mathrm{~s}$. All three batches of GP-C solubilized completely within $120 \mathrm{~s}$. Averaged time of complete dissolution of GP-B, -D, and -E were statistically longer 
than BNM, with GP-B (longer than $180 \mathrm{~s}$ ) being the most difficult to dissolve. Besides, only one of the three batches of GP-F was completely dissolved within 120 s, while the other two batches required longer than $130 \mathrm{~s}$.

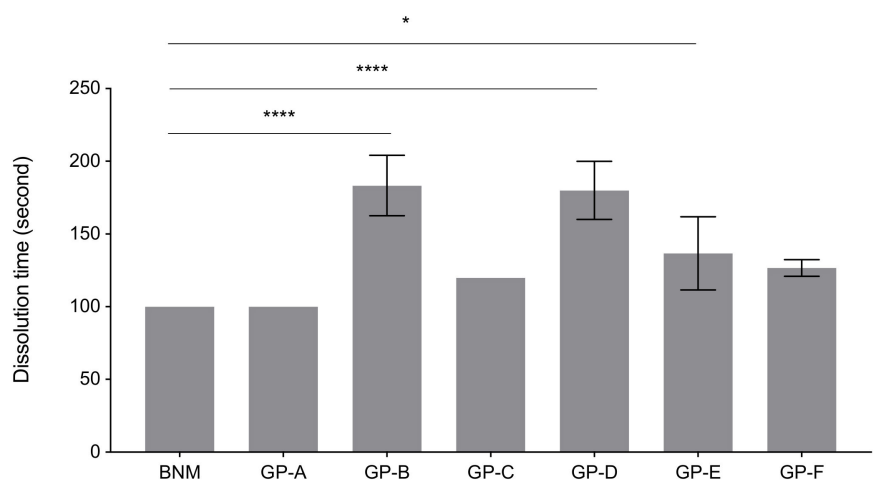

Figure 2. Comparison of dissolution time under laboratory conditions between BNM and six GPs $\left(\mathrm{N}=3\right.$ batches. $p<0.05$ was considered statistically significant. $\left.{ }^{* * * *} p<0.0001,{ }^{*} p<0.05\right)$.

Results of dissolution time measured under simulated clinical conditions are presented in Figure 3. The shortest mean dissolution time for BNM and GP-A was $84 \pm 11$ and $84 \pm 16$ s, respectively. On the other hand, GP-D needed a significantly longer time to dissolve (366 $\pm 108 \mathrm{~s}$ ), while the mean dissolution time for GP-B and $-\mathrm{C}$ was $149 \pm 26$ and $210 \pm 30$ s, respectively. For inter-batch comparison, the visual dissolution time of GP-C and -D differed between the batches $(p<0.05)$. GP-E and -F came in containers that were smaller than the regular clinical size $(10 \mathrm{~mL})$. Therefore, comparison of dissolution time of GP-E and -F to BNM was not tested in this study.
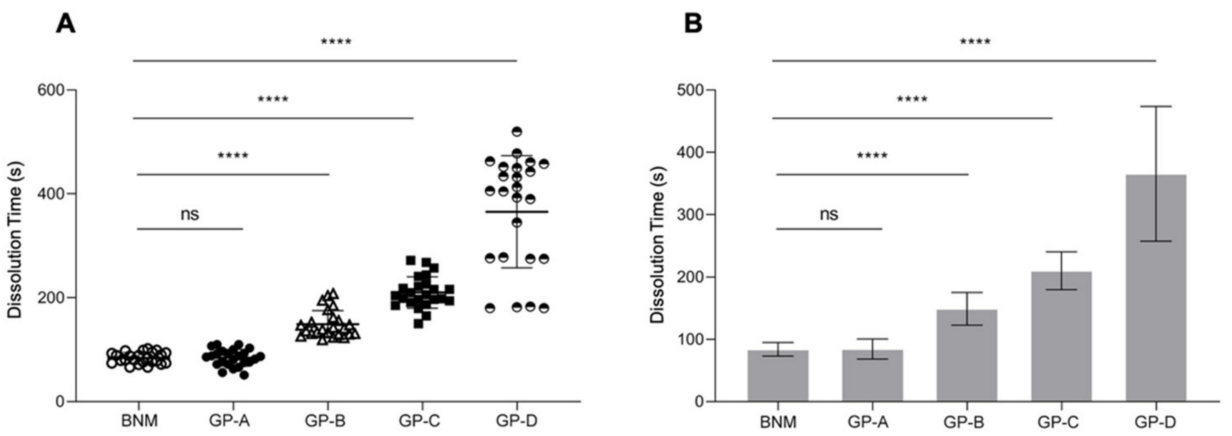

Figure 3. Comparison of dissolution time under simulated clinical conditions between BNM and six GPs (A): each dot represents one sample, 3 batches of samples were tested for each product, 8 samples tested for each batch; (B): data presented as mean \pm standard deviation, ns: not significant $(* * * * p<0.0001)$.

\subsection{Insoluble Particles Quantification}

Comparisons of numbers of insoluble particles with diameters greater than $10 \mu \mathrm{m}$ (Figure 4A) and $25 \mu \mathrm{m}$ (Figure 4B) for BNM and GPs are presented in Figure 4. Among all the products tested, GP-D appeared to contain the highest number of insoluble particles larger than $10 \mu \mathrm{m}$ in diameter, as well as more insoluble particles larger than $25 \mu \mathrm{m}$ in diameter. No insoluble particles larger than $25 \mu \mathrm{m}$ in diameter were observed in all three batches of BNM and GP-E. 
A

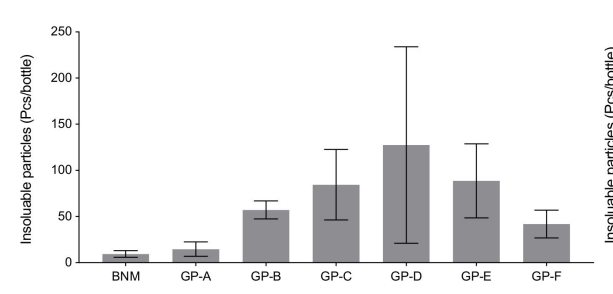

B

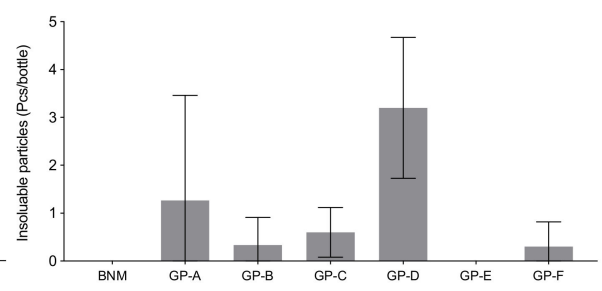

Figure 4. Number of insoluble particles detected in three batches of BNM and GPs (A): particle diameter greater than $10 \mu \mathrm{m},(B)$ : particle diameter greater than $25 \mu \mathrm{m}$ ( $\mathrm{N}=3$ batches).

\subsection{Solution Stability}

The stability of the solution was evaluated by the percentage of open-ring metabolites of BNM and GP solutions over time. In order to prove that the percentage of open-ring metabolites in meropenem solution is representative of solution stability, we measured the percentage of meropenem remaining within the BNM solution over time and compared it with the percentage of the open-ring metabolites of BNM, which is showed in Figure 5A. It can be observed that the percentage of meropenem decreased while open-ring metabolites increased as a function of time, demonstrating the usefulness of open-ring metabolites in representing stability of meropenem solutions. The open-ring metabolites showed a tendency to increase over time for both the BNM solution and the GPs. GP-D and -A showed higher open-ringed metabolite concentrates over time, and GP-D demonstrated the fastest increase in metabolites from $0-4 \mathrm{~h}$. At $4 \mathrm{~h}$, all GPs showed comparable stability. At 6 h, GP-C, -E, and -F solutions showed lower concentrates of open-ring metabolite. At $6 \mathrm{~h}$ and $8 \mathrm{~h}, \mathrm{BNM}$ showed the lowest open-ringed metabolite concentrates.

A

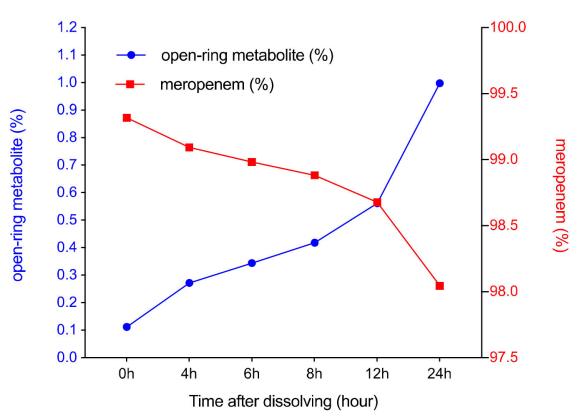

B

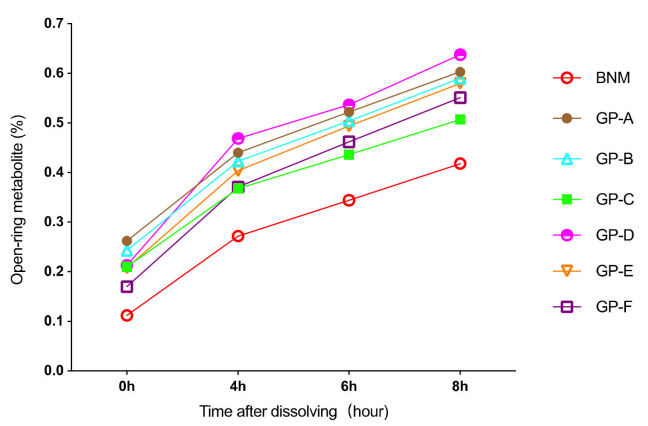

Figure 5. Comparisons of meropenem solution stabilities between BNM and GPs over time. (A) Changes in percentages of open-ring metabolites and remaining meropenem within the BNM solution over time. (B) Changes in open-ring metabolite concentrations within BNM and GPs solutions over time. Each line represents the average of three batches for each product.

\subsection{Residual Solvent Detection}

Residual solvent in meropenem solution was detected by gas-chromatography-mass spectrometry (GC-MS). For residual solvent, GP-A showed maximum acetone in all batches $(0.23 \%)$, while ethanol and ethyl acetate were detected in both GP-E $(0.09 \%, 0.01 \%)$ and GP-F $(0.08 \%, 0.01 \%)$. (Figure 6) 

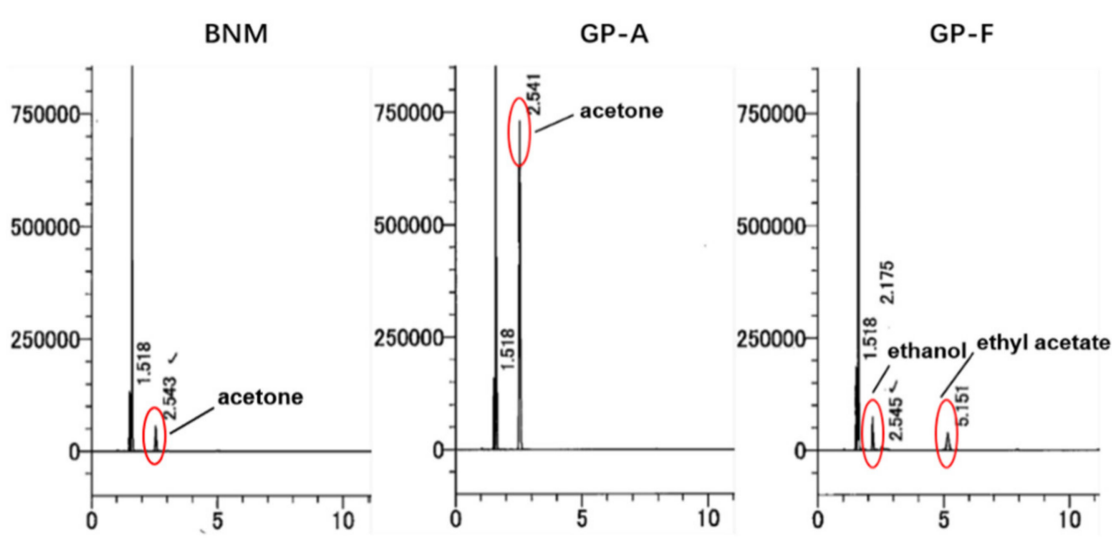

Figure 6. Chromatograms of the residual solvents in solutions of BNM (left) and GPs (middle and right). Red circles highlight peaks that indicate residual solvents (acetone, ethanol, and ethyl acetate) detected by headspace gas chromatography.

\subsection{Antimicrobial Susceptibility Test}

Table 1 summarizes the results of antimicrobial susceptibility testing of BNM and six GPs against clinical isolates of Pseudomonas aeruginosa (P. aeruginosa). No significant differences were observed in the antimicrobial action between GPs and BNM. However, the $\mathrm{MIC}_{88}$ of GP-B, $-\mathrm{D}$, and $-\mathrm{F}$ was higher than the other four products $(8 \mu \mathrm{g} / \mathrm{mL})$. The highest concordance rate was demonstrated by GP-A (89.5\%) and -E (88.5\%).

Table 1. Antimicrobial susceptibility in vitro. MIC $(\mu \mathrm{g} / \mathrm{mL})$ and concordance rate (\%) of each GP's MIC to BNM against clinical isolates of P. aeruginosa.

\begin{tabular}{ccccccccc}
\hline & \multicolumn{3}{c}{ MIC $(\boldsymbol{\mu g} / \mathbf{m L})$} & \multicolumn{3}{c}{ Concordance Rate $(\%)$ of the MIC } \\
\cline { 2 - 9 } & MIC Range & MIC $_{\mathbf{5 0}}$ & $\mathbf{M I C}_{\mathbf{8 0}}$ & $\mathbf{M I C}_{\mathbf{8 8}}$ & $\times \mathbf{1}$ & $\times \mathbf{2}$ & $\times \mathbf{4}$ & $\times \mathbf{8}$ \\
\hline BNM & $<0.6-32$ & 0.5 & 2 & 4 & $\mathrm{n} / \mathrm{a}$ & $\mathrm{n} / \mathrm{a}$ & $\mathrm{n} / \mathrm{a}$ & $\mathrm{n} / \mathrm{a}$ \\
GP-A & $0.125-32$ & 0.5 & 4 & 4 & 89.5 & 10.5 & 0 & 0 \\
GP-B & $0.125-32$ & 0.5 & 2 & 8 & 85 & 14 & 1 & 0 \\
GP-C & $0.125-32$ & 0.5 & 2 & 4 & 87.5 & 12 & 0.5 & 0 \\
GP-D & $0.125-32$ & 0.5 & 2 & 8 & 88 & 11.5 & 0.5 & 0 \\
GP-E & $0.125-32$ & 0.5 & 2 & 4 & 88.5 & 11 & 0.5 & 0 \\
GP-F & $0.125-32$ & 0.5 & 2 & 8 & 86.5 & 12 & 1.5 & 0 \\
\hline
\end{tabular}

$\mathrm{MIC}_{50}, \mathrm{MIC}_{80}, \mathrm{MIC}_{88}=$ MIC inhibits $50 \%, 80 \%, 88 \%$ of tested isolates. $\mathrm{n} / \mathrm{a}=$ not applicable.

Concordance rate was calculated as the percentage of the GP's MIC that was equal to one, two, four, and eight times BNM's MIC.

\section{Discussion}

Differences between brand-name meropenem and meropenem generics marketed in foreign countries, including Japan [19], India [22], and European countries [11], have been reported by several studies [11,19-22]. This study, for the first time, characterized critical pharmaceutical features, including particle morphologies, solubility, numbers of insoluble particles, stability, residual solvents, and antimicrobial effects, of BNM and six major GPs marketed in China.

Although no statistically significant differences were observed in the HPLC quantification and the antimicrobial activity test, the BNM differs from the GPs in some pharmaceutical characteristics.

Previous studies characterized open-ring metabolites to be one of the major degradation products of meropenem, which are generated almost immediately after reconstitution $[23,24]$. Our results supported their findings by showing opposite trends of open-ring metabolites and meropenem concentrations in solution over time. The BNM solution remained stable for a little longer than GPs. The stability in the solution (reflected by 
open-ringed metabolites) was related to the quality of the formulation [25]. Meropenem with higher stability may be beneficial for clinical applications such as prolonged infusion. The instructions for meropenem recommended that the shelf-life of the saline-reconstituted solution to be $6 \mathrm{~h}$ before intravenous administration at room temperature. Therefore, prolonged infusion of meropenem solution during clinical applications should not be exceeding $6 \mathrm{~h}$. Our results supported this finding: At $6 \mathrm{~h}$ post-reconstitution, BNM solution contained the minimum open-ring metabolites.

It has been shown by previous studies conducted in Japan that all eight meropenem generics marketed in Japan took a statistically longer time than brand-name meropenem to completely dissolve [19]. This study used similar methods to visualize meropenem particle morphologies of brand-name meropenem and its six generics under SEM and found that GP-A and -C were similar to the $40 \mathrm{~nm}$ of BNM, while for the other GPs, the diameter was $>80 \mathrm{~nm}$. A uniformity of mixing was observed in BNM.

Meropenem can be dissolved in $0.9 \%$ sodium chloride solution, $5 \%$ glucose solution, and glucose sodium chloride solution during intravenous application, in which the $0.9 \%$ sodium chloride solution is the most commonly used. Our study focused on the first and the most critical step of reconstitution in actual clinical applications-dissolving meropenem power in a small volume (usually $10 \mathrm{~mL}$ ) of saline solution within its original vial. The difference in dissolution time might be related to the morphology of particles [26] (size and uniformity under SEM) and the uniformity in mixing. The particle size of the BNM was the smallest, which could arise due to variations in the recrystallization process [27] during manufacturing. In the current study, GP-B, -C, and -D required a long time to dissolve. One GP showed the same dissolution time of approximately $84 \mathrm{~s}$ as the BNM. In this study, the time of dissolution was subjectively and visually observed under simulated clinical conditions; the dissolution time was also tested under laboratory conditions.

In addition, according to the Chinese Pharmacopeia [28], insoluble particles for intravenous administration should not be exceeding 6000 for particles with diameters greater than or equal to $10 \mu \mathrm{m}$ and 600 for particles with diameters greater than or equal to $25 \mu \mathrm{m}$ per $1 \mathrm{~g}$ of sample. Our results indicated that while BNM and GPs both met the criteria of the Chinese Pharmacopeia, the number of insoluble particles in some GPs was larger than that in the BNM. According to the International Council for Harmonisation (ICH) of Technical Requirements for Pharmaceuticals for Human Use Guideline for Residual Solvents Q3C(R8) [29], acetone, ethanol, and ethyl acetate belong to Class 3 solvents, which are solvents with low toxic potential to humans. The limits of acetone, ethanol, and ethyl acetate in The Chinese Pharmacopoeia (2020) do not exceed 0.5\%, which means that all products were in line with the limits of the Pharmacopoeia. The number of solvent residues between the BNM and GPs differed, which might be associated with the manufacturing technique and quality control of the generics.

P. aeruginosa has been shown to be one of the major causes of nosocomial infections, such as hospital-acquired pneumonia, sepsis, and bloodstream infections [30]. Treatment of $P$. aeruginosa-induced infections can be challenging due to its emergent resistance and limited choice of antibiotics [31]. P. aeruginosa isolates have been widely used to examine in vitro antimicrobial efficacy of meropenem [32,33]. Previous studies have examined MIC of brand-name meropenem and three generics marketed in Europe against P. aeruginosa isolates obtained from ICU and observed no statistical significances among these products, although some deviated results were observed [11]. Consistently, our study showed similar MIC against $P$. aeruginosa between BNM and six GPs, suggesting that generics showed reasonable equivalence with the BNM in terms of their antimicrobial activities, although the concordance rate was lower than $90 \%$. Previous studies conducted in Japan have shown similar results [19].

Nevertheless, the present study has some limitations. The antimicrobial activity comparisons of BNM and GPs were only performed against P. aeruginosa. It is possible that significant differences in MIC against other bacteria strains may be detected between BNM and GPs. In addition, all the tests were conducted in vitro in laboratory conditions, and BE 
was not evaluated in animals or humans. Further clinical studies based on these findings may need to be implemented using brand-name meropenem and its generics.

\section{Materials and Methods}

\subsection{Study Design and Subjects}

The pharmaceutical characteristics of the BNM (Mepem ${ }^{\circledR}$, Sumitomo Dainippon Pharma Co., Ltd., Osaka, Japan.) and its six major generic products (GPs) in China were assessed by SEM: dissolution time in both simulated clinical conditions and laboratory conditions, insoluble particles, solution stability, residual solvent, and antimicrobial susceptibility in three batches. The six GPs were represented by GP-A, -B, -C, -D, -E, and $-\mathrm{F}$, respectively. The names of BNM and GPs were blinded to experimental personnel in all assessments.

\subsection{Particle Morphology Characterization under SEM}

Dry powder of BNM and each GP was examined using SEM to observe the morphology of the crystal particle [19] (Keyence, VE-8800, Osaka, Japan). The samples were added on a rectangular carbon tape attached to metal stubs; the excess powder was removed using compressed air. Then, the samples were placed in a sputter coater operated at $40 \mathrm{~mA}$ for 2 min (MSP-1S, Vacuum Device, Mito, Japan) for gold coating. The images were captured at $2 \mathrm{kV}$.

\subsection{Dissolution Time Measurements}

The dissolution tests were performed under both laboratory and simulated clinical conditions.

The dissolution time under laboratory condition was evaluated based on the time taken by $0.5 \mathrm{~g} \mathrm{BNM}$ or GPs to dissolve in $5 \mathrm{~mL}$ normal saline at $25{ }^{\circ} \mathrm{C}$ with oscillation at 150 times/min on a constant temperature oscillator (SN200SD thermostatic water tank by Nissinrika, Tokyo, Japan and TRL-107NHF compact portable cooler by Thomas, Tokyo, Japan).

Dissolution time measured under simulated clinical conditions was recorded as the average of the observation by four pharmacists individually. Three batches of each product were tested. The pharmacists prepared BNM and its GPs in a clinical situation. Ten milliliters of saline were injected into the ampoule to dissolve $0.5 \mathrm{~g}$ BNM or GP-A, $-\mathrm{B},-\mathrm{C}$, and -D. The dissolution was promoted by slight manual shaking. The time (s) required for the preparation of the solution to achieve complete dissolution of drug powder was observed by the naked eye and recorded. The average dissolution time was determined by the results obtained from four pharmacists for each batch of drugs and further compared to determine statistical significance.

In simulated clinical conditions, GP-E and -F were dissolved in $5 \mathrm{~mL}$ normal saline owing to the limitation of bottle size. This dissolution time may be different from that for those dissolved in 10-mL normal saline. Therefore, the dissolution time of GP-E and -F may be different from other products which were dissolved in 10-mL saline. Based on this consideration, data of dissolution time of GP-E and -F under simulated clinical condition was excluded from statistical analyses.

\subsection{Insoluble Particles Quantification}

Insoluble particles were detected by HIAC/ROYCO particles counter [34] (System 3000 A with a HRLD-150CE sensor) with the following parameters: flow velocity of $10 \mathrm{~mL} / \mathrm{min}$; the capacity and times of measurement were $5 \mathrm{~mL} \times 4$ times. Three batches were tested for each product. Numbers of particles with diameters larger than $10 \mu \mathrm{m}$ and $25 \mu \mathrm{m}$ were measured and analyzed in a respective manner. 


\subsection{Solution Stability}

Meropenem solution stability test was performed using a HPLC system with a specialized UV detector (Shimadzu LC-20A, Kyoto, Japan). Instrument control, data acquisition and processing were controlled by LabSolutionsCS (ver. 6.84, Shimadzu). Reference meropenem standard was diluted in $0.1 \%$ triethylamine solution and used as an external standard to determine concentrations of meropenem and the open-ring metabolites in reconstituted solution (manufactured by Sumitomo Dainippon Pharma Co., Ltd., Oita, prepared by SCAS, Oita). Meropenem standard was diluted to $0.5 \mathrm{mg} / \mathrm{mL}$ to determine the concentration of remaining meropenem and $0.025 \mathrm{mg} / \mathrm{mL}$ to determine the concentration of the open-ring metabolites in solution, respectively. Each sample was diluted to $0.5 \mathrm{mg} / \mathrm{mL}$ in $0.1 \%$ triethylamine. Ten microliters of diluted sample were injected onto a liquid chromatography system (Column: $150 \times 4.6 \mathrm{~mm}, 5 \mu \mathrm{m}$ column filled with octadecylsilyl silica gel). The mobile phase was composed of $0.1 \%$ triethylamine and acetonitrile (93.5: 6.5, vol/vol) [28]. Meropenem retention time was $6.1 \mathrm{~min}$, the open-ring metabolites retention time was $3.5 \mathrm{~min}$. Wavelength of the UV detector was set to $220 \mathrm{~nm}$ and temperature of the column was set constantly to $25^{\circ} \mathrm{C}$. BNM and six GPs were tested at $0,4,6$, and $8 \mathrm{~h}$ after dissolution in $10 \mathrm{~mL}$ normal saline at $25^{\circ} \mathrm{C}$.

\subsection{Residual Solvent Detection}

Residual solvent measurement of BNM and six GPs was performed using a qualified gas chromatography system (Shimadzu GC-2010 Plus) equipped with a headspace sampler (HS-20) following the instructions of the Chinese Pharmacopeia [28]. The headspace operating conditions are as follows: sample line temperature: $100{ }^{\circ} \mathrm{C}$, transfer line temperature: $140{ }^{\circ} \mathrm{C}$. Helium was used as the carrier gas at a constant flow rate. A capillary column (Column: $0.53 \mathrm{~mm} \times 30 \mathrm{~mm}, 3.0 \mu \mathrm{m}$ column coated with $100 \%$ dimethylpolysiloxane) of $40{ }^{\circ} \mathrm{C}$ was used to separate residual solvents from each sample in the gas chromatography system.

\subsection{Antimicrobial Susceptibility Test}

The antimicrobial susceptibility test was performed on a total of 200 non-duplicate clinical isolates of P. aeruginosa selected for this study and preserved on a bacterial bead (Microbank, IWAKI \& Co., Ltd., Tokyo, Japan) at $-80{ }^{\circ} \mathrm{C}$ at the Tohoku Medical and Pharmaceutical University. The minimum inhibitory concentration (MIC) was determined using the broth microdilution method $[35,36]$ according to a standard procedure in accordance with the Clinical and Laboratory Standards Institute (CLSI) recommendations [37].

\subsection{Statistical Analysis}

Statistical analysis was conducted using SPSS Statistics for Windows, Version 17.0. The comparisons in the means and standard deviations of continuous variables with a normal distribution were performed using Student's $t$-test. The median and range of continuous variables with a skewed distribution were compared using Wilcoxon rank-sum test. The $p$-values were based on two-sided tests and $<0.05$ was considered statistically significant.

\section{Conclusions}

In conclusion, although no statistically significant differences were observed in the HPLC quantification and the antimicrobial activity test, the studied meropenem generics were different from the brand-name meropenem in some pharmaceutical characteristics, such as stability, dissolution time, and morphology, as assessed by electron microscopy.

Author Contributions: Conceptualization, S.F. and S.Z.; data curation, P.Y. and M.K.; formal analysis, P.Y.; funding acquisition, Z.Z.; investigation, P.Y., S.F., Y.D., B.Z., L.Y. and M.K.; methodology, P.Y., S.F, L.Y., Z.Z. and S.Z.; project administration, Z.Z.; resources, Z.Z.; supervision, S.Z.; writingoriginal draft, P.Y.; writing-review \& editing, S.F. and S.Z. This study was a collaboration between several research institutions. Researchers in Peking University Third Hospital contributed to the evaluation of dissolution time in simulated clinical conditions. Sumika Chemical Analysis Service in Japan contributed to dissolution time in laboratory, stability, and residual solvent. Researchers in 
Tohoku Medical and Pharmaceutical University studied the morphology by electron microscopy and antibacterial activity. All authors have read and agreed to the published version of the manuscript.

Funding: This study was funded by Sumitomo Pharmaceutical (Suzhou) Co. Ltd. (Grant No.: H56495-32).

Data Availability Statement: The datasets used and/or analyzed during the current study are available from the corresponding author on reasonable request.

Acknowledgments: The authors acknowledge Jiewen Li, Shanzhong Zhang, and Hiroki Uemukai of Sumitomo Pharmaceutical (Suzhou) Co. Ltd. for reviewing this manuscript.

Conflicts of Interest: The authors declare no conflict of interest.

\section{References}

1. Collier, R. Drug patents: The evergreening problem. Can. Med. Assoc. J. 2013, 185, E385-E386. [CrossRef] [PubMed]

2. Manzoli, L.; Flacco, M.E.; Boccia, S.; Andrea, D.E.; Panic, N.; Marzuillo, C.; Siliquini, R.; Ricciardi, W.; Villari, P.; Ioannidis, J.P.A. Generic versus brand-name drugs used in cardiovascular diseases. Eur. J. Epidemiol. 2016, 31, 351-368. [CrossRef]

3. Morgan, S.G.; Leopold, C.; Wagner, A.K. Drivers of expenditure on primary care prescription drugs in 10 high-income countries with universal health coverage. Can. Med. Assoc. J. 2017, 189, E794-E799. [CrossRef]

4. Segal, J.B.; Onasanya, O.; Daubresse, M.; Lee, C.-Y.; Moechtar, M.; Pu, X.; Dutcher, S.K.; Romanelli, R.J. Determinants of Generic Drug Substitution in the United States. Ther. Innov. Regul. Sci. 2019, 54, 151-157. [CrossRef] [PubMed]

5. Cox, A.L.; El-Sayed, M.H.; Kao, J.-H.; Lazarus, J.V.; Lemoine, M.; Lok, A.S.; Zoulim, F. Progress towards elimination goals for viral hepatitis. Nat. Rev. Gastroenterol. Hepatol. 2020, 17, 533-542. [CrossRef]

6. Pathak, H. Capsule Commentary on Romanelli et al., Predictors of Statin Compliance after Switching from Branded to Generic Agents Among Managed-Care Beneficiaries. J. Gen. Intern. Med. 2014, 29, 1391. [CrossRef]

7. Gauzit, R.; Lakdhari, M. Generic antibiotic drugs: Is effectiveness guaranteed? Méd. Mal. Infect. 2012, 42, 141-148. [CrossRef]

8. Duan, Y.; Wang, W.; Ren, J. Use of carbapenems in urban hospitals in China. Shanghai Yiyao 2009, 30, 370-372.

9. Wouters, O.J.; Kanavos, P.G.; McKee, M. Comparing Generic Drug Markets in Europe and the United States: Prices, Volumes, and Spending. Milbank Q. 2017, 95, 554-601. [CrossRef]

10. Spelsberg, A.; Prugger, C.; Doshi, P.; Ostrowski, K.; Witte, T.; Hüsgen, D.; Keil, U. Contribution of industry funded post-marketing studies to drug safety: Survey of notifications submitted to regulatory agencies. BMJ 2017, 356, j337. [CrossRef] [PubMed]

11. Delattre, I.K.; Briquet, C.; Wallemacq, P.; Tulkens, P.M.; Van Bambeke, F. Comparative in vitro antimicrobial potency, stability, colouration and dissolution time of generics versus innovator of meropenem in Europe. Int. J. Antimicrob. Agents 2019, 55, 105825. [CrossRef]

12. Cojutti, P.; Sartor, A.; Righi, E.; Scarparo, C.; Bassetti, M.; Pea, F. Population Pharmacokinetics of High-Dose Continuous-Infusion Meropenem and Considerations for Use in the Treatment of Infections Due to KPC-Producing Klebsiella pneumoniae. Antimicrob. Agents Chemother. 2017, 61, e00794-17. [CrossRef] [PubMed]

13. Griffith, D.C.; Sabet, M.; Tarazi, Z.; Lomovskaya, O.; Dudley, M.N. Pharmacokinetics/Pharmacodynamics of Vaborbactam, a Novel Beta-Lactamase Inhibitor, in Combination with Meropenem. Antimicrob. Agents CH 2019, 63, e01659-18. [CrossRef] [PubMed]

14. Dhillon, S. Meropenem/Vaborbactam: A Review in Complicated Urinary Tract Infections. DRUGS 2018, 78, 1259-1270. [CrossRef]

15. Pascale, R.; Giannella, M.; Bartoletti, M.; Viale, P.; Pea, F. Use of meropenem in treating carbapenem-resistant Enterobacteriaceae infections. Expert Rev. Anti Infe. 2019, 17, 819-827. [CrossRef]

16. Patel, T.S.; Pogue, J.M.; Mills, J.P.; Kaye, K.S. Meropenem-vaborbactam: A new weapon in the war against infections due to resistant Gram-negative bacteria. Futur. Microbiol. 2018, 13, 971-983. [CrossRef] [PubMed]

17. Jorgensen, S.C.J.; Rybak, M.J. Meropenem and Vaborbactam: Stepping up the Battle against Carbapenem-resistant Enterobacteriaceae. Pharmacother. J. Hum. Pharmacol. Drug Ther. 2018, 38, 444-461. [CrossRef]

18. Shields, R.K.; McCreary, E.K.; Marini, R.V.; Kline, E.G.; Jones, E.C.; Hao, B.; Chen, L.; Kreiswirth, B.N.; Doi, Y.; Clancy, C.J.; et al. Early Experience with Meropenem-Vaborbactam for Treatment of Carbapenem-resistant Enterobacteriaceae Infections. Clin. Infect. Dis. 2020, 71, 667-671. [CrossRef]

19. Fujimura, S.; Watanabe, A. Generic antibiotics in Japan. J. Infect. Chemother. 2012, 18, 421-427. [CrossRef]

20. Agudelo, M.; Rodriguez, C.A.; Pelaez, C.A.; Vesga, O. Even Apparently Insignificant Chemical Deviations among Bioequivalent Generic Antibiotics Can Lead to Therapeutic Nonequivalence: The Case of Meropenem. Antimicrob. Agents CH 2014, 58, 1005-1018. [CrossRef]

21. Ordóñez, K.; Feinstein, M.M.; Reyes, S.; Hernández-Gómez, C.; Pallares, C.; Villegas, M.V. Clinical and economic impact of generic versus brand name meropenem use in an intensive care unit in Colombia. Braz. J. Infect. Dis. 2019, 23, 237-245. [CrossRef] [PubMed]

22. Das, P.; Jana, B.; Dhar, K.; Goel, G.; Bhattacharya, S.; Chandy, M. Relative Potency of Different Generic Brands of Meropenem, Colistin and Fosfomycin: Implications for Antimicrobial Therapy and Antimicrobial Formulary. Indian J. Med. Microbiol. 2019, 37, 95-98. [CrossRef] 
23. Barbosa, F.D.S.; Pezzi, L.C.; Tsao, M.; Macedo, S.M.D.; de Oliveira, T.F.; Schapoval, E.E.; Mendez, A.S. Stability in clinical use and stress testing of meropenem antibiotic by direct infusion ESI-Q-TOF: Quantitative method and identification of degradation products. J. Pharm. Biomed. Anal. 2020, 179, 112973. [CrossRef] [PubMed]

24. Elragehy, N.A.; Abdel-Moety, E.M.; Hassan, N.Y.; Rezk, M.R. Stability-indicating determination of meropenem in presence of its degradation product. Talanta 2008, 77, 28-36. [CrossRef] [PubMed]

25. Khan, Z.A.; Tripathi, R.; Mishra, B. Floating Elementary Osmotic Pump Tablet (FEOPT) for Controlled Delivery of Diethylcarbamazine Citrate: A Water-Soluble Drug. AAPS PharmSciTech 2011, 12, 1312-1323. [CrossRef]

26. Yung, M.M.N.; Fougères, P.; Leung, Y.H.; Liu, F.; Djurišić, A.B.; Giesy, J.P.; Leung, K.M.Y. Physicochemical characteristics and toxicity of surface-modified zinc oxide nanoparticles to freshwater and marine microalgae. Sci. Rep. UK 2017, 7, 15909. [CrossRef]

27. Gigliobianco, M.R.; Casadidio, C.; Censi, R.; Di Martino, P. Nanocrystals of Poorly Soluble Drugs: Drug Bioavailability and Physicochemical Stability. Pharmaceutics 2018, 10, 134. [CrossRef] [PubMed]

28. Commission, C.P. Chinese Pharmacopoeia; China Medical Science Press: Beijing, China, 2020.

29. Guideline ICH. International Council for Harmonisation of Technical Requirements for Pharmaceuticals for Human Use. Available online: https://database.ich.org/sites/default/files/ICH_Q3C-R8_Guideline_Step4_2021_0422_1.pdf (accessed on 8 May 2021).

30. Berube, B.J.; Rangel, S.M.; Hauser, A.R. Pseudomonas aeruginosa: Breaking down barriers. Curr. Genet. 2016, 62, 109-113. [CrossRef]

31. Ibrahim, D.; Jabbour, J.-F.; Kanj, S.S. Current choices of antibiotic treatment for Pseudomonas aeruginosa infections. Curr. Opin. Infect. Dis. 2020, 33, 464-473. [CrossRef]

32. Zahra, M.J.; Hamed, H.; Mohammad, R.Y.; Nosratollah, Z.; Akbarzadeh, A.; Morteza, M. Evaluation and study of antimicrobial activity of nanoliposomal meropenem against Pseudomonas aeruginosa isolates. Artif. Cells Nanomed. Biotechnol. 2017, 45, 975-980. [CrossRef]

33. Hu, Y.; Liu, C.; Wang, N.; Shih, S. In vitro antibacterial activity of rifampicin in combination with imipenem, meropenem and doripenem against multidrug-resistant clinical isolates of Pseudomonas aeruginosa. BMC Infect. Dis. 2016, 16, 444. [CrossRef] [PubMed]

34. Feld, G.K.; Tiongson, J.; Oshodi, G. Particle formation and risk of embolization during transseptal catheterization: Comparison of standard transseptal needles and a new radiofrequency transseptal needle. J. Interv. Card. Electrophysiol. 2011, 30, 31-36. [CrossRef] [PubMed]

35. Ruimy, R.; Angebault, C.; Djossou, F.; Dupont, C.; Epelboin, L.; Jarraud, S.; Lefevre, L.A.; Bes, M.; Lixandru, B.E.; Bertine, M.; et al. Are Host Genetics the Predominant Determinant of Persistent NasalStaphylococcus aureus Carriage in Humans? J. Infect. Dis. 2010, 202, 924-934. [CrossRef]

36. Bharat, A.; Cunningham, S.A.; Scott Budinger, G.R.; Kreisel, D.; DeWet, C.J.; Gelman, A.E.; Waites, K.; Crabb, D.; Xiao, L.; Bhorade, S.; et al. Disseminated Ureaplasma infection as a cause of fatal hyperammonemia in humans. Sci. Transl. Med. 2015, 7, 284re3. [CrossRef] [PubMed]

37. CLSI. Performance Standards for Antimicrobial Susceptibility Testing. In Proceedings of the 22nd Informational Supplement CLSI M100-S22; CLSI: Wayne, PA, USA, 2012. 